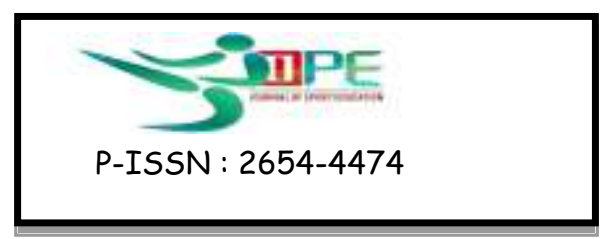

\title{
HUBUNGAN KELENTUKAN PERGELANGAN TANGAN DAN POWER OTOT LENGAN-BAHU DENGAN HASIL AKURASI SMASH BULUTANGKIS PUTRA PADA PB. ANGKASA PEKANBARU
}

\author{
Arisman, ${ }^{1}$ Drs.Saripin,S.Pd, M.Kes, AIFO, ${ }^{2}$ Aref Vai, S.Pd, M.Pd $^{3}$ \\ arisman.rohul@gmail.com,sarifinunri@gmail.com,aref.vai@lecture.unri.ac.id
}

\section{ABSTRAK}

Masalah dalam penelitian ini adalah terlihat bahwa kemampuan smash mereka masih kurang baik, arah cock datar dan tidak menukik, pukulannya gampang dikembalikan, jalan bola tidak kencang, cock sering keluar lapangan atau tidak mengarah pada sasaran dan juga masih ada yang menyangkut di net. Hal ini diduga karena kelentukan pergelangan tangan dan power otot lengan-bahu yang sehingga mengakibatkan akurasi smash tidak mengarah pada arah sasaran smash. Penelitian ini bertujuan mengetahui apakah terdapat Hubungan Kelentukan Pergelangan Tangan dan Power otot lengan-bahu Dengan Hasil Akurasi Smash Bulutangkis Putra Pada PB. Angkasa Pekanbaru. Teknik pengambilan sampel yaitu keseluruhan populasi (total sampling) atlet bulutangkis putra PB. Angkasa Pekanbaru berjumlah 8 orang. Penelitian ini menggunakan teknik korelasi. Kemudian, tes data menggunakan tes normalitas, tes produk momen korelasi, dan tes bahwa $\mathrm{L}_{\text {hitung }}$ variabel $\mathrm{X} 1=$ $0,254, \mathrm{~L}_{\text {hitung }}$ variabel $\mathrm{X} 2=0,140$ dan $\mathrm{L}_{\text {hitung }}$ variabel $\mathrm{Y}=0,190$ dimana $\mathrm{L}_{\text {tabel }}$ diperoleh $0,285(\alpha=0,05)$, dengan demikian $\mathrm{L}_{\text {hitung }}=0,254<\mathrm{L}_{\text {tabel }} 0,285$ pada variabel $\mathrm{X} 1, \mathrm{~L}_{\text {hitung }}$ $0,140<\mathrm{L}_{\text {tabel }}=0,285$ pada variabel X2 dan $\mathrm{L}_{\text {hitung }}=0,190<\mathrm{L}_{\text {tabel }}=0,285$ pada variabel $\mathrm{Y}$, dengan kata lain disimpulkan bahwa data X1, X2 dan Y berdistribusi normal.

Kata Kunci: kelentukan pergelangan tangan, power otot lengan-bahu, akurasi smash

\section{ABSTRACT}

The problem in this research is seen that their smash ability is still not good, the direction of cock flat and not dip, easy punch returned, the way the ball is not tight, the cock is often out of the field or does not lead to the target and also there is still a concern on the net. This matter allgedly doe to the lack of wrist and arm muscle power that is not good so that the smash accuracy does not lead to the target smash. The study aims to determine whether there is a correlation between the formation of the wrist and arm muscle power whit the result of the smash accuracy badminton son on PB. Angkasa Pekanbaru. Sampling technique that is the whole population (total sampling) badminton athlete PB. Angkasa son Pekanbaru numbered 8 people. This research uses correlation technique. Then, the test data using the normality test, product moment correlation test, and test that $L_{\text {calculate }}$ variable $X 1=0,254$, $L_{\text {calculate }}$ variable $X 2=0,140$ and $L_{\text {calculate }}$ variable $Y=0,190$ where $L_{\text {table }}$ obtained 0,285 ( $\alpha$ $=0,05)$, with So $L_{\text {calculate }}=0,254<L_{\text {table }} 0,285$ on variable $X 1, L_{\text {count }} 0,140<L_{\text {table }}=0,285$ on the variable $X 2$ and $L_{\text {arithmetic }}=0,190<L_{\text {table }}=0,285$ on variable $Y$, in other words it is concluded that X1, X2 and $Y$ data are distributed normal. 


\section{PENDAHULUAN}

Olahraga merupakan salah satu bagian aktivitas dalam hidup manusia, karena dengan olahraga seseorang dapat menjaga kesehatan dan kebugaran tubuhnya. Selain untuk menjaga kebugaran tubuh, masih ada manfaat lain dari olahraga itu bisa untuk prestasi dan juga rekreasi. Olahraga prestasi ialah olahraga yang diperlombakan baik skala nasional maupun internasional yang diatur dengan seperangkat peraturan yang telah ditentukan. Di indonesia olahraga prestasi semakin berkembang seiring keinginan bangsa indonesia untuk memajukan bidang olahraga, karena dengan olahraga indonesia bisa dikenal oleh negara-negara lain, selain itu juga bidang industri olahraga nya. Olahraga prestasi bisa mengharumkan nama negara dikancah internasional. Hal ini menunjukan pembinaan bidang olahraga sangat berperan penting dalam mewujudkan cita-cita pembangunan nasional.

Sehubungan dengan hal ini pemerintah mengeluarkan UndangUndang Sistem Keolahragaan Nasional (No.3 tahun 2005 pasal 1): "pembinaan dan pembangunan keolahragaan nasional dapat menjamin pemerataan akses terhadap olahraga, peningkatan kesehatan dan kebugaran, peningkatan prestasi dan management keolahragaan yang mampu menghadapi tantangan serta tuntutan perubahan kehidupan nasional dan global merupakan sistem keolahragaan nasional".

Upaya peningkatan prestasi olahraga yang setinggi-tingginya merupakan tujuan utama olahraga prestasi, dengan prestasi yang tinggi

$$
\text { olahraga dapat dijadikan }
$$

sebagai salah satu cara untuk mengharumkan nama bangsa dan negara. Untuk itu perlu diperhatikan dalam faktor penunjang prestasi baik internal maupun exsternal, faktor internalnya yaitu bakat dan motivasi, sedangkan exsternalnya kualitas latihan, agar hasil yang dicapai tidak mengecewakan dan merupakan pencapaian hasil yang maksimal.

Berbagai cabang olahraga yang sedang giat dalam peningkatan prestasi atletnya, begitu juga dengan cabang olahraga bulutangkis. Olahraga bulutangkis sudah dikenal sejak lama, sehingga olahraga ini merupakan salah satu cabang olahraga yang cukup populer dikalangan masyarakat indonesia. Olahraga ini menarik minat berbagai kelompok umur, berbagai tingkat keterampilan, baik pria maupun wanita memainkan olahraga ini didalam atau diluar ruangan untuk rekreasi maupun sebagai ajang untuk persaingan dalam prestasi. Untuk menjadi pemain bulutangkis yang berprestasi, maka harus menguasai bermacam-macam teknik dasar bermain bulutangkis dengan baik dan benar. Dengan modal berlatih tekun, disiplin, terarah dibawah bimbingan pelatih yang berkualitas baik maka kita dapat menguasai teknik dasar dengan baik dan benar pula. Menurut Marta Dinata (2006:1), berbagai jenis-jenis teknik yang harus dikuasai adalah service, lop, dropshot, smash, undurhand, dan drive.

Salah satu dari teknik di atas yang diamati yaitu smash. Smash merupakan pukulan yang cepat, diarahkan kebawah dengan kuat, dan tajam, untuk mengembalikan bola pendek yang telah dipukul keatas (Toni Grice, 2007:85). Pukulan itu identik dengan pukulan menyerang. Karna itu tujuannya untuk mematikan bola kelapangan lawan. Karakteristik pukulan ini adalah keras, laju jalan nya cock cepat menuju lantai lapangan, sehingga pukulan ini membutuhkan aspek kekuatan otot tungkai, lengan, bahu, dan kelentukan (fleksibilitas), pergelangan tangan serta koordinasi gerak tubuh yang harmonis (Marta Dinata, 2006:15).

Kelentukan atau flexibility merupakan kemampuan pergelangan/persendian untuk dapat melakukan gerakan ke semua arah dengan amplitudo gerakan (range of motion) yang besar dan luas sesuai dengan fungsi persendian yang digerakkan (Syafruddin, 2012:111). Adapun yang termasuk dalam kelentukan yaitu tentang kemampuan fungsi persendian, seperti sendi bahu, lutut, kaki, pinggul, pergelangan tangan dan lain-lain. Kemampuan kelentukan ditandai oleh keluasan gerakan yang dapat dilakukan pada persendian/pergelangan. Daya ledak 
merupakan salah satu dari komponen biomotorik yang penting dalam olahraga. Karena daya ledak akan menentukan seberapa keras orang dapat memukul, seberapa jauh melempar, seberapa tinggi melompat, seberapa cepat berlari dan sebagainya, (Arsil, 2000:71). Telah diterangkan bahwa daya ledak otot sangat diperlukan dalam melempar atau mengayun dan memukul lebih keras. Pukulan smash merupakan pukulan overhand (atas) yang diarahkan kebawah dan dilakukan dengan penuh tenaga. Pukulan ini identik sebagai pukulan menyerang, karena tujuan utamanya untuk mematikan bola pada lapangan lawan. Dalam melakukan pukulan smash membutuhkan aspek kekuatan otot tungkai, lengan, bahu, dan fleksibilitas pergelangan tangan serta koordinasi gerak tubuh yang harmonis (Huang Hua, 2007:41)

Namun berdasarkan hasil penelitian yang peneliti lakukan pada club bulutangkis putra PB. Angkasa pekanbaru terlihat bahawa kemampuan smash mereka kurang baik, arah cock datar dan tidak menukik, pukulannya mudah untuk dikembalikan, bola tidak kencang, cock sering keluar lapangan atau tidak mengarah tepat sasaran terkadang masih ada yang menyangkut dinet. Hal ini diduga karena kelentukan pergelangan tangan dan power otot lengan-bahu sehingga mengakibatkan akurasi smash tidak mengarah pada arah sasaran smash.

Mencermati keadan tersebut dan dari hasil observasi, maka untuk membuktikan permasalahan yang ada, peneliti tertarik untuk melakukan penelitian ilmiah dengan judul "Hubungan Kelentukan Pergelangan Tangan dan power Otot Lengan-bahu Dengan Hasil Akurasi Smash Bulutangkis puta PB. Angkasa pekanbaru".

1.

\section{Pergelangan Tangan \\ Dalam \\ permainan}

bulutangkis banyak faktor yang harus diperhatikan. Salah satu faktor adalah kondisi fisik antara lain, fleksibilitas. Sebab fleksibilitas ini sangat menunjang dalam keterampilan melakukan pukulan smash pada permainan bulutangkis. Sebagaimana yang dikemukakan oleh Harsono (1988:163) bahwa: “Orang yang fleksibel adalah orang yang mempunyai ruang gerak yang luas dalam sendi-sendinya dan mempunyai suatu otot yang elastis, biasanya terbatas ruang gerak sendi-sendinya. Jadi faktor utama yang membantu menentukan fleksibilitas adalah elastisnya otot" . Dalam melakukan aktivitas olahraga unsur fleksibilitas sangatlah diperlukan untuk tidak terjadinya suatu yang tidak kita inginkan seperti cedera terutama pada persendian.

Fleksibilitas adalah keefektifan seseorang dalam mengulurkan seluas-luasnya terutama otot-otot, ligamen pada sekitar persendian (M. Sajoto, 1988:17). Dengan demikian, orang yang lentuk adalah orang yang mempunyai ruang gerak yang luas dalam sendi-sendinya serta mempunyai otot yang elastis. Jadi salah satu faktor turut membantu menentukan fleksibilitas pergelangan tangan adalah elastisnya otot, seperti yang dikemukakan oleh Sadoso Sumosardjuno bahwa: "Fleksibilitas adalah kapasitas fungsional persendian untuk menggerakkan pada daerah yang maksimal tergantung pada panjang otot dan ligamen disekitar persendian".

$$
\text { Jadi kelentukan }
$$

pergelangan tangan, akan dapat menimbulkan kemampuan untuk melakukan gerak sendi dari berbagai arah di dalam melakukan pukulansmash dimana tangan yang akan sangat berpengaruh dalam melakukan pukalan pada sasaran yang diinginkan. Dengan demikian berdasarkan uraianuraian di atas maka dapat disimpulkan bahwa kelentukan pergelangan tangan turut menunjang dalam melakukan pukulan smash dalam permainan bulutangkis. 
2. Hakekat Power Otot Lenganbahu

Telah diketahui bahwa betapa pentingnya kekuatan bagi hampir semua cabang olahraga. Oleh karena itu latihan strength harus senantiasa masuk dalam program latihan kondisi fisik untuk pemain. Akan tetapi apakah kekuatan sudah cukup bagi pemain untuk meningkatkan prestasinya, jawabannya tentu belum cukup karena orang yang memiliki kekuatan saja atau yang kuat ototnya belum cukup dengan sendirinya akan berprestasi tinggi apabila tidak mempunyai otot-otot yang cepat. Oleh karena itu pemain yang hanya sekedar berlatih untuk meningkatkan kekuatannya saja, akan tetapi kekuatan tersebut haruslah ditingkatkan menjadi daya ledak (power).

$$
\text { Daya ledak lebih }
$$

diperlukan dan boleh dikatakan semua cabang olahraga, oleh karena itu di dalam daya ledak terdapat unsur fisik yaitu kekuatan dan kecepatan. Harsono $(1988,199)$ mengatakan bahwa: "Power is product of force and velocity, this is probably more important than absolute strength alone." Dapat diartikan; daya ledak adalah hasil kekuatan dan kecepatan, kekuatan absolut sendiri.

Selanjutnya M. Sajoto (1988:17) mengemukakan: Power adalah kemampuan seseorang untuk melakukan kekuatan maksimum, dengan usahanya yang dikerahkan dalam waktu sependek-pendeknya. Dalam hal ini dikatakan bahwa daya ledak otot atau power = kekuatan atau (force) x kecepatan atau velocity.

Pendapat tersebut di atas menyebutkan dua unsur yang penting dalam daya ledak yaitu kekuatan otot dan kecepatan otot dalam mengerahkan tenaga maksimal untuk mengatasi tahanan, sehingga dengan demikian dapat disimpulkan batasan daya ledak adalah kemampuan otot untuk mengerahkan kekuatan maksimal dalam waktu yang sangat cepat.

\section{Hakekat Akurasi Smash}

Smash merupakan senjata yang sangat ampuh untuk mengumpulkan angka dalam suatu pertandingan bulutangkis. Hal itu disebabkan sifat jatuhnya bola yang kencang dan tajam. Dalam melakukan smash, shuttle harus dipukul ke bawah dengan sudut jatuh sebesar mungkin, sudut jatuh ini lebih penting daripada kecepatan shuttle. Oleh karena itu, usahakan memukul pada ketinggian semaksimum mungkin. Bidang raket mengarah ke bawah pada saat persentuhan raket dengan shuttle berada di muka tubuh anda. Gerakan putar dari lengan bawah dan pergelangan tangan sangat cepat dan bertenaga, sehingga shuttle melayang dengan cepat dan lurus ke arah bawah (James Poole, 1982:35).

Beberapa petunjuk untuk melakukan pukulan smash adalah sebagai berikut :

a. Sentuhlah shuttle pada saat ia berada di muka tubuh anda, dan lakukan hal itu dengan lengan terentang.

b. Pada saat persentuhan, pergelangan tangan dan lengan bawah harus berputar dengan saat cepat.

c. Pada saat persentuhan, bidang raket berada dalam posisi datar agak menuju ke bawah.

d. Pukullah shuttle dengan keras.

e. Sudut jatuh yang tajam lebih penting daripada kecepatan luncur shuutle.

f. Jangan melakukan smash lebih ke belakang dari tiga per empat bidang lapangan anda.

\section{METODE PENELITIAN}

Penelitian ini adalah merupakan penelitian korelasional dengan membandikan hasil pengukuran dua variabel yang berbeda agar dapat menentukan tingkat hubungan antara variabelvariabel tersebut (Arikunto, 2006:270).

Untuk menentukan besar hubungan antara variabel $\mathrm{X}$ dan variabel $\mathrm{Y}$ dinyatakan dengan Korelasi Produk Moment (Zulfan, $2007: 104)$ 
$r_{x y}=\frac{n \Sigma X Y-\Sigma X \Sigma Y}{\sqrt{n \Sigma X^{2}-(\Sigma X)^{2}} \sqrt{n \Sigma Y^{2}-(\Sigma Y)^{2}}}$

$r_{\mathrm{X} 1 \mathrm{X} 2 \mathrm{Y}}=\sqrt{\frac{\mathrm{r}^{2} \mathrm{X} 1 \mathrm{Y}+\mathrm{r}^{2} \mathrm{X} 2 \mathrm{Y}-2(\mathrm{rX} 1 \mathrm{Y})(\mathrm{rX} 2 \mathrm{Y})(\mathrm{rX} 1 \mathrm{X} 2)}{1-\mathrm{r}^{2} \mathrm{X} 1 \mathrm{X} 2}}$

$\mathrm{r}_{\mathrm{x} 1 \mathrm{x} 2 \mathrm{y}}=$ koefisien korelasi antara $\mathrm{X} 1$, $\mathrm{X} 2$ dan $\mathrm{Y}$

$\mathrm{r}^{2} \mathrm{X} 1 \mathrm{Y}=$ korelasi variabel bebas 1 dengan variabel $Y$

$r^{2} \mathrm{X} 2 \mathrm{Y}=$ kerelasi variabel bebas 2 dengan variabel $Y$

$\mathrm{r}^{2} \mathrm{X} 1 \mathrm{X} 2=$ korelasi variabel bebas 1 dengan variabel bebas 2 $\mathrm{Y} \quad=$ jumlah seluruh skor $\mathrm{Y}$

Jadi untuk dapat menghitung korelasi ganda, maka harus dihitung terlebih dahulu korelasi sederhananya dulu melalui korelasi perductmoment dari pearson (Sugiyono, 233:2013).

\section{a. Populasi}

Populasi merupakan keseluruhan subjek penelitian (Arikunto, 2006:130). Populasi dalam penelitian ini adalah atlet bulutangkis putra PB. Angkasa Pekanbaru yang berjumlah 8 orang.

\section{b. Sampel}

Menurut Arikunto (2006:13), sampel adalah sebagian atau wakil populasi yang diteliti. Mengingat jumlah populasi kurang dari 100 orang, maka seluruh populasi dijasikan sampel (total sampling) yaitu sebanyak 8 orang. Hal ini sesuai dengan Arikunto (2006:134) “apabila jumlah subjeknya kurang dari 100 orang, lebih baik diambil semua sehingga penelitiannya merupakan penelitian populasi.

\section{HASIL DAN PEMBAHASAN}

Data yang melalui tes dan pengukuran terhadap 8 orang subjek penelitian membahas tentang hubungan kelentukan pergelangan tangan yang dilambangkan dengan (X1), power otot lengan-bahu dilambangkan dengan (X2) sebagai variabel bebas, dan hasil akurasi smash bulutangkis dilambangkan dengan (Y) sebagai veriabel terikat. Data yang diperolehsebagai hasil penelitian adalah data kuantitatif melalui serangkaian tes dan pengukuran terhadap 8 orang atlet bulutangkis yang merupakan sampel dari club bulutangkis $\mathrm{Pb}$. Mandiri Pekanbaru. Adapun data dari variabel bebas dan variabel terikat yaitu sebagai berikut:

\section{Kelentukan Pergelangan Tangan}

Penelitian kelentukan

pergelangan tangan menggunakan Goniometer dari 8 orang subjek diperoleh data tertinggi yaitu 85 derajat dan terendah 65 derajat, rata-rata 77,3 dan standar deviasi 6,24. Lebih jelas tentang pengukuran dapat dilihat pada tabel distribusi frekuensi di bawah ini:

\section{Tabel 1. Distribusi kelentukan} pergelangan tangan

\begin{tabular}{|c|c|c|c|}
\hline $\begin{array}{l}\mathrm{N} \\
\mathrm{o} .\end{array}$ & $\begin{array}{c}\text { Kelas } \\
\text { interv } \\
\quad \text { al }\end{array}$ & $\begin{array}{c}\text { Frekue } \\
\text { nsi } \\
\text { absolut } \\
\text { e }\end{array}$ & $\begin{array}{c}\text { Frekue } \\
\text { nsi } \\
\text { relative }\end{array}$ \\
\hline 1 & $\begin{array}{c}65- \\
69\end{array}$ & 1 & $12,5 \%$ \\
\hline 2 & $\begin{array}{c}70- \\
74\end{array}$ & 2 & $25 \%$ \\
\hline 3 & $\begin{array}{c}75- \\
79\end{array}$ & 2 & $25 \%$ \\
\hline 4 & $\begin{array}{c}80- \\
84\end{array}$ & 2 & $25 \%$ \\
\hline 5 & $\begin{array}{c}85- \\
89\end{array}$ & 1 & $12,5 \%$ \\
\hline \multicolumn{2}{|c|}{ Jumlah } & 8 & $100 \%$ \\
\hline
\end{tabular}

Berdasarkan

hasil distribusi frekuensi di atas dari 8 subjek, ternyata 1 orang sampel $(12,5 \%)$ dengan rentang nilai 65 69 dikategorikan kurang, kemudian 2 orang sampel (25\%) dengan rentang nilai $70-74$ dikategorikan kurang, kemudian 2 orang sampel (25\%) dengan rentang nilai $75-79$ dikategorikan kurang baik, kemudian 2 orang sampel (25\%) dengan rentang nilai $80-84$ dikategorikan baik, kemudian 1 orang sampel ( $12,5 \%)$ dengan rentang nilai 85 - 89 dikategorikan sangat baik. 
Untuk lebih jelas lihat histogram di bawah ini:

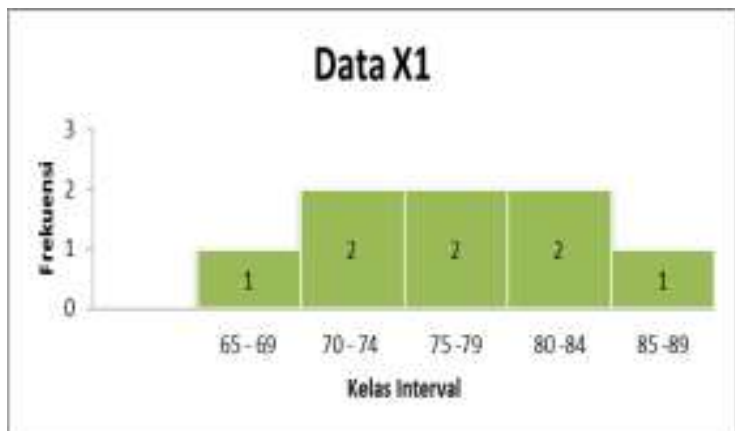

Gambar 1. Histogram kelentukan pergelangan tangan.

\section{Power Otot Lengan - Bahu}

Berikut ini diuraikan dari hasil tes power otot lengan dari 8 orang sampel dimana nilai tertinggi adalah 320 dan nilai terendah 150 , rata-rata 250 dan standar deviasi 61,75. Untuk lebih jelasnya dibuatkan tabel distribusi frekuensi di bawah ini:

Tabel 2. Distribusi power otot lengan

\begin{tabular}{|c|c|c|c|}
\hline $\begin{array}{c}\text { No } \\
\cdot\end{array}$ & $\begin{array}{c}\text { Kelas } \\
\text { interva } \\
1\end{array}$ & $\begin{array}{c}\text { Frekuens } \\
\text { i absolut }\end{array}$ & $\begin{array}{c}\text { Frekuens } \\
\text { i relative }\end{array}$ \\
\hline 1 & $\begin{array}{c}150- \\
191,5\end{array}$ & 2 & $25 \%$ \\
\hline 2 & $\begin{array}{c}192,5 \\
-234\end{array}$ & 2 & $25 \%$ \\
\hline 3 & $\begin{array}{c}235- \\
276,5\end{array}$ & 2 & $25 \%$ \\
\hline 4 & $\begin{array}{c}277,5 \\
-319\end{array}$ & 1 & $12,5 \%$ \\
\hline 5 & $\begin{array}{c}320- \\
361,5\end{array}$ & 1 & $12,5 \%$ \\
\hline & Jumlah & 8 & $100 \%$ \\
\hline
\end{tabular}

Berdasarkan hasil distribusi frekuensi di atas dari 8 orang sampel, ternyata 2 orang sampel (25\%) dengan rentang nilai 150 - 191,5 dikategorikan kurang , kemudian 2 orang sampel (25\%) dengan rentang nilai 192,5 - 234 dikategorikan kurang, kemudian 2 orang sampel (25\%) dengan rentang nilai 235 - 276,5 dikategorikan kurang baik, kemudian 1 orang sampel $(12,5 \%)$ dengan rentang nilai $277,5-$ 319 dikategorikan baik, dan 1 orang sampel $(12,5 \%)$ dengan rentang nilai 320 - 361,5 dikategorikan sangat baik.

Untuk lebih jelasnya

lihat histogram di bawah ini:

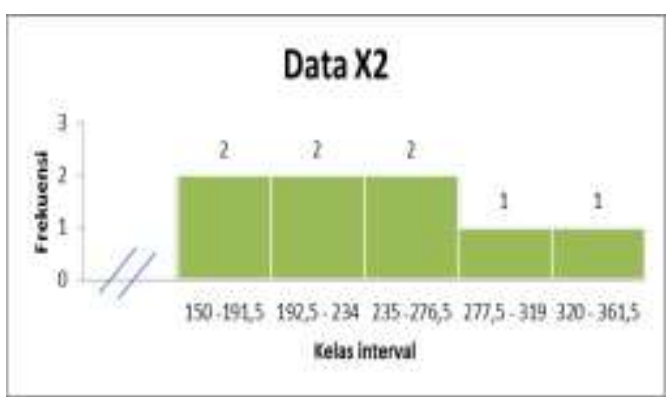

Gambar 2. Histogram power otot lengan-Bahu.

\section{Hasil Akurasi Smash Bulutangkis}

Berikut ini diuraikan data hasil smash bulutangkis dari 8 orang sampel dimana nilai tertinggi yaitu 19 dan nilai terendah 11, ratarata 15 dan standar deviasi 2,03. Untuk lebih jelasnya dapat dibuat distribusi frekuensi di bawah ini.

Tabel 3. Distribusi frekuensi akurasi smash bulutangkis

\begin{tabular}{|c|c|c|c|}
\hline $\begin{array}{c}\text { No } \\
\text {. }\end{array}$ & $\begin{array}{c}\text { Kelas } \\
\text { interva } \\
1\end{array}$ & $\begin{array}{c}\text { Frekuens } \\
\text { i absolut }\end{array}$ & $\begin{array}{l}\text { Frekuens } \\
\text { i relative }\end{array}$ \\
\hline 1 & $\begin{array}{c}11- \\
12\end{array}$ & 2 & $25 \%$ \\
\hline 2 & $\begin{array}{c}13- \\
14\end{array}$ & 1 & $12,5 \%$ \\
\hline 3 & $\begin{array}{c}15- \\
16 \\
\end{array}$ & 4 & $50 \%$ \\
\hline 4 & $\begin{array}{c}17- \\
18\end{array}$ & 0 & $0 \%$ \\
\hline 5 & $\begin{array}{c}19- \\
20\end{array}$ & 1 & $12,5 \%$ \\
\hline \multicolumn{2}{|c|}{ Jumlah } & 8 & $100, \%$ \\
\hline
\end{tabular}

Berdasarkan hasil distribusi frekuensi di atas dari 8 orang sampel ternyata 2 orang (25\%) dengan rentang nilai $11-12$ dikategorikan kurang, kemudian 1 orang $(12,5 \%)$ dengan rentang nilai 13 - 14 dikategorikan kurang, kemudian 4 orang $(50 \%)$ dengan rentang nilai 15 - 16 dikategorikan kurang baik, kemudian 0 orang $(0 \%)$ dengan rentang nilai $17-18$ dikategotikan baik dan 1 orang (12,5\%) dengan rentang nilai 19 20 dikategorikan sangat baik.

Untuk lebih jelasnya lihat histogram di bawah ini: 


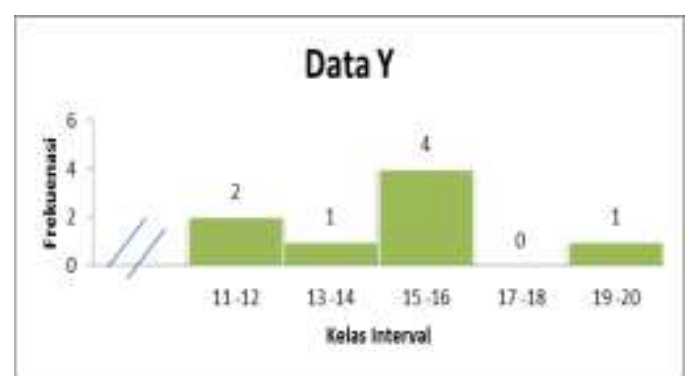

Gambar 3. Histogram akurasi smash bulutangkis.

\section{Pembahasan Hasil Penelitian}

Penelitian ini bertujuan untuk mengetahui hubungan kelentukan pergelangan tangan dan power otot lengan-bahu dengan hasil akurasi smash bulutangkis putra pada PB.Angkasa Pekanbaru yang berjumlah 8 orang. Sampel dalam penelitian ini kurang dari seratus maka sampel diambil secara (total sampling) atau teknik pengambilan sampel secara penuh pemain PB.Angkasa Pekanbaru yang berjumlah 8 orang. Rancangan penelitian ini merupakan penelitian korelasional dengan membandingkan hasil pengukuran dua variabel yang berbeda agar dapat menentukan tingkat hubungan antara variabel-variabel. Sebagai variabel bebas kelentukan pergelangan tangan $\left(\mathrm{X}_{1}\right)$ dan power otot lengan-bahu $\left(\mathrm{X}_{2}\right)$ sedangkan variabel terikat (Y) adalah hasil akurasi smash. Instrumen dalam penelitian ini berupa tes diantaranya Tes kelentukan pergelangan tangan dengan menggunakan test Goniometer, Tes power otot lengan-bahu dengan menggunakan Two hand medicine ball put dan Tes Hasil akurasi smash.

Berdasarkan

perhitungan korelasi antara kelentukn pergelangan tangan $\left(\mathrm{X}_{1}\right)$ terhadap hasil akurasi smash (Y) menggunakan rumus korelasi product moment terdapat hubungan. Bersarkan analisis dilakukan, maka didapat rata-rata kelentukan 77,3 dan simpangan baku 6,24. Untuk skor rata-rata akurasi smash didapat 15 dengan simpangan baku 2,03. Dari keterangan di atas diperoleh analisis korelasi antara kelentukan dengan akurasi smash, dimana $r_{\text {tab }}$ pada taraf signifikan a $(0.05)=$ berarti $R_{\text {hitung }}(0,850)>r_{\text {tab }}$ (0.707), artinya hipotesis diterima.

Kemudian berdasarkan perhitungan korelasi antara kelincahan $\left(\mathrm{X}_{2}\right)$ terhadap kemampuan menggiring bola (Y) menggunakan rumus korelasi product moment terdapat hubungan. Bersarkan analisis dilakukan, maka didapat rata-rata kemampuan akurasi smash 15 dan simpangan baku 2,03. Untuk skor rata-rata power otot lengan-bahu didapat 2.50 dengan simpangan baku 61,75. Dari keterangan di atas diperoleh analisis korelasi antara kelentukan dan hasil akurasi smash, dimana $r_{\text {tab }}$ pada taraf signifikan a $(0.05)=$ berarti $R_{\text {hitung }}$ $(0,732)>r_{\text {tab }}(0.707)$, artinya hipotesis diterima. Berdasarkan perhitungan korelasi antara kelentukan $\left(\mathrm{X}_{1}\right)$ dan power otot lengan-bahu $\left(\mathrm{X}_{2}\right)$ terhadap hasil akurasi smash (Y) menggunakan rumus korelasi product moment terdapat hubungan secara bersamasama antara kelentukan dan power otot lengan-bahu terhadap hasil akurasi smash bulutangkis putra PB.Angkasa, dimana $r_{\text {tab }}$ pada taraf signifikan $\alpha$ $(0,05)=0,456$, berarti $R_{\text {hitung }}(0,857)>$ $r_{\text {tab }}(0,707)$. Dengan kata lain disimpulkan Ha diterima.

\section{KESIMPULAN DAN SARAN Kesimpulan}

Berdasarkan pengamatan dan observasi peneliti di lapangan bersama pelatih bahwa kemampuan smash pemain PB.Angkasa kurang baik, arah cock datar dan tidak menukik, pukulannya mudah untuk dikembalikan, bola tidak kencang, cock sering keluar lapangan atau tidak mengarah tepat pada sasaran, terkadang masih ada yang menyangkut di net. Hal ini diduga karena kelentukan pergelangan tangan dan power otot lengan-bahu sehingga mengakibatkan akurasi smash tidak mengarah pada arah sasaran smash.

Populasi dalam penelitan seluruh pemain (putra) PB.Angkasa pekanbaru. Dalam penelitian ini adalah PB.Angkasa pekanbaru yang berjumlah 8 orang. Sampel dalam penelitian ini kurang dari seratus maka sampel diambil secara (total sampling) atau teknik pengambilan sampel secara penuh pemain PB.Angkasa pekanbaru yang berjumlah 8 orang. Penelitian ini merupakan penelitian korelasional dengan membandingkan hasil pengukuran dua variabel yang berbeda agar dapat menentukan tingkat hubungan antara variabel-variabel ini (Arikunto, 2006:273). Sebagai variabel bebas kelentuntukan pergelangan 
tangan $\left(\mathrm{X}_{1}\right)$ dan power otot lenganbahu $\left(\mathrm{X}_{2}\right)$ sedangkan variabel terikat (Y) adalah hasil akurasi smash. Instrumen dalam penelitian ini berupa tes diantaranya Tes Kelentukan pergelangan tangan dengan menggunakan test goniometer, Tes power otot lengan-bahu dengan menggunakan Two hand madicine ball put dan Tes akurasi smash.

Berdasarkan dari hasil penelitian yang telah penulis uraikan pada bab terdahulu, maka dapat diambil kesimpulan sebagai berikut: Terdapat hubungan antara kelentukan pergelangan tangan, dimana $r_{\text {tab }}$ pada taraf signifikan $\alpha(0,05)=0,456$ berarti $r_{\text {hitung }}(0,850)>r_{\text {tab }}(0,707)$. Kemudian Terdapat hubungan antara power otot lengan-bahu , dimana $r_{\text {tab }}$ pada taraf signifikan $\alpha(0,05)=0,456$, berarti $r_{\text {hitung }}(0,732)>r_{\text {tab }}(0,707)$, dan Terdapat hubungan secara bersamasama antara kelentukan pergelangan tangan dan power otot lengan-bahu terhadap hasil akurasi smash pemain PB.Angkasa pekanbaru, dimana $r_{\text {tab }}$ pada taraf signifikan $\alpha(0,05)=0,456$, berarti $R_{\text {hitung }}(0,857)>r_{\text {tab }}(0,707)$.

\section{Rekomendasi}

Berdasarkan kesimpulan di atas, maka peneliti dapat memberikan rekomendasi kepada:

1. Pelatih dapat memperhatikan kelentukan pergelangan tangan dan power otot lengan untuk menghasilkan akurasi smash yang baik bagi .

2. Pelatih dapat mengarahkan latihan yang dapat mempengaruhi kemampuan akurasi smash.

3. Atlet agar dapat memperhatikan dan menerapkan latihan kelentukan dan power otot lengan untuk menunjang keterampilan akurasi smash.

4. Bagi para peneliti disarankan untuk dapat mengkaji faktor-faktor lain yang berhubungan dengan kemampuan akurasi smash

\section{DAFTAR PUSTAKA}

Arikunto, Suharsimi. 2006. Prosedur Penelitian Suatu Pendekatan Praktik. Jakarta. Rineka Cipta.

Arsil,1999. Pembinaan Kondisi Fisik. Padang. FIK.UNP.

Dinata, Marta. 2006. Bulutangkis. Jakarta. Cerdas Jaya.
Grice, Toni. 2007. Bulutangkis, Petunjuk praktisuntuk Pemula dan Lanjut. Jakarta. Raja Grafindo Persada. Harsono. 1988. Choaching dan AspekAspek Psikologis dalam Choaching. Jakarta. Tambak Kusuma.

Hua, Huang. 2007. Bulutangkis, Olahraga Kegemaranku. Klaten Intan Perwira.

Ismaryati. 2008. Tes dan Pengukuran Olahraga. Surakarta. UNS pres.

Kosasih, Engkos. 1985. Olahraga, Teknik dan program Latihan. Jakarta. Akademika Pressindo.

Nelson, Barry dalam Willyandari Sudjatmiko. Korelasi Antara Power Tungkai, Power Lengan, Dan Fleksibilitas Pergelangan Tangan Terhadap Haasil Tembakan Bebas Cabang Olahraga Basket. 2014.

Poole, James. 1982. Belajar Bulutangkis. Bandung. Pionir.

Riandari, Henny dalam Yon Maryono. Hubungan otot lengan dan bahu dan hasil kelentukan punggung lempar cakram. 2016.

Sajoto. 1988. Peningkatan dan Kekuatan Kondisi Fisik dalam Olahraga. Semarang. Dahara Prize.

Sugiyono. 2013. Statistika untuk penelitian, bandung

Syafruddin. 2012. Ilmu Kepelatihan Olahraga. Padang. UNP Pres Padang. Zulfan. 2007. Statistik untuk Ilmu-Ilmu Sosial. Pekanbaru. Cendika Insani 